\title{
Requests for euthanasia and assisted suicide: A qualitative study of the wordings of requests from patients at the end of life hospitalised in palliative care units.
}

Florence Mathieu-Nicot ( $\square$ florence.mathieunicot@gmail.com )

Centre Hospitalier Universitaire de Besancon https://orcid.org/0000-0001-7341-2063

Aline Chassagne

Centre Hospitalier Universitaire de Besancon

Daniele Leboul

pole recherche et enseignement universitaire maison médicale Jeanne Garnier

Anne Bousquet

Pole recherche et enseignement maison médicale Jeanne Garnier

\section{Aurélie Godard-Marceau}

Centre d'Investigation Clinique Besançon

Hélène Trimaille

Centre Hospitalier Universitaire de Besancon

\section{Frédéric Guirimand}

Pole recherche et enseignement Maison Médicale Jeanne Garnier

\section{Elodie Cretin}

Universite Bourgogne Franche-Comte

\section{Régis Aubry}

Centre hospitalier Universitaire de Besançon

\section{Research article}

Keywords: Wish to Hasten Death, Request for euthanasia, Request for physician assisted suicide, Qualitative study, Palliative Care, Evolution, wordings

Posted Date: December 18th, 2019

DOI: https://doi.org/10.21203/rs.2.18924/v1

License: (9) This work is licensed under a Creative Commons Attribution 4.0 International License. Read Full License 


\section{Abstract}

Background Whilst euthanasia and assisted suicide are forbidden by French Law, patients at the end of life, hospitalized in Palliative Care Units, sometimes express the Wish to Hasten their Death. Few Studies have analyzed the formulation of these patient requests in interviews and the associated death-related representations. The DESA study analyzed the expression of patients' requests, focusing on the terms and how patients worded their wishes. The aim is to identify from the "raw wording" of the patients' requests, the means of expressing them in all its singularity and evolution.

Methods This is a qualitative study that took place in 11 French Palliative care Units during on year and included adult patients who had made an explicit request (euthanasia or physician assisted suicide) to a health care provider. Semi-structured interviews were conducted within 48 hours of the initial request (D0), then a week later (D7).

Results At DO, the initial request is a request for euthanasia and it calls a third person urgently. This request is related to physical and psychological suffering, trauma and representations of death. At D7, we observe a semantic change; the request is less explicit and requires less intervention by a third party. The quest remains that of a death without suffering.

Conclusions These patients express themselves easily on their request and listening is necessary to be able to hear the meaning of the words but also their functions. It is their nuance, variety and evolution that help to understand what the requirements mean.

Trial registration number : ClinicalTrials.gov Identifier: NCT02845817

\section{Background}

Regardless of whether or not the legislative framework allows euthanasia and medically assisted suicide, patients at the end of life sometimes express the wish to hasten their death (WTHD). Recent studies into requests for preemptive death reveal the realities and the relative frequency of such requests ${ }^{1}$. The data which attempts to quantify WTHD appear approximative most probably due to variabilities in the declarations, definitions and interpretations of a WTHD. One study published in $2016^{2}$ attempts to define the meaning of WTHD by international consensus. Whilst beyond those definitions produced by experts, several articles concentrate on the points of view of the patients expressing a WTHD ${ }^{34}$. The findings of a number of qualitative studies on the subject reveal the heterogeneity of the expression of the WTHD, as well as that of the meaning to the patients of their requests ${ }^{5} 6$. Furthermore, the expression of the WTHD evolves over time (Guirimand et al., 2014; Ohnsorge et al 2014). This explains the need for a thorough qualitative analysis of the terms patients use and of the way they evolve. Our study (DESA Study ${ }^{7}$ ) analysed the expressions of patients' WTHD in palliative care unit (PCU), focusing on the terms and the way patients worded their requests for euthanasia or assisted suicide. The aim of this article is to identify 
from the "raw wording" of the patients' requests, the means of expressing their WTHD in all its plurality, singularity and evolution.

The analysis additionally shows evidence of the representations of the act of euthanasia as well as those of death in the patients encountered.

\section{Methods}

The study took place in 11 PCU: 151 beds in two different regions of France (REF-Region Est France, the east of France, and RIF-lle de France, Paris and the surrounding region). This study received the favorable opinion of the committee for the Protection of Persons (CPP Est II) on 15/05/2014 and the National Agency for the Safety of Medicines and Health Products (ANSM) on 09/05/2014, in accordance with the legislation in force.

The study involved adult patients who had made a Requests for Euthanasia and Assisted Suicide (REAS) to a health care provider, that is to say an explicit request for euthanasia or physician assisted suicide ${ }^{8}$. The requests that were defined as 'explicit' were those made verbally using direct terms of reference such as: "give me an injection" or "help me to end it all". Patients who expressed a desire to be dead without implying an explicit action from a third party (such as: "I don't want to be here anymore") were excluded. The health care provider who received the request transcribed the patient's initial wording in their medical records, as faithfully as possible. These data enabled an initial analysis of the occurrence of terms.

A qualitative study was carried out on the initial wording. Semi-structured interviews were carried out within 48 hours of the initial request (first interview, D0), then a week later (second interview, D7). When a patient had expressed an explicit request for help in dying, the health care provider would contact the researcher, after having obtained informed consent from the patient (to participate and for publications) and confirmation that their condition permitted them to be interviewed. Generally, the interviews with these patients at the end of life began with an open question in reference to the initial terms used by the patient in their request, urging them to describe the request, to name the WTHD, then express themselves on the meaning of their request and what had motivated it. The interviews were recorded and retranscribed word for word, anonymously and confidentially. The interviews were directed by four researchers (three psychologists and a socio-anthropologist).

The period of data collection, from October 2014 to November 2015, enabled the sample predefined from two preliminary studies 910 to be obtained.

Analysis of the wording used by patients to express their request for help in dying was applied to the initial statements reported in the medical records, as well as on the words obtained during the two rounds of interviews with the patients.

The wordings were cross-analysed between different researchers during regular working meetings. Various patient situations were coded by all the researchers to ensure harmonisation between the codes' 
descriptions and their definitions. From these codings, a thematic tree was designed and completed, and later refined as the analyses progressed. In the subsequent meetings, various analytical concepts finally emerged.

\section{Results}

\section{I/ Inclusions.}

Thirty-one initial responses were reported verbatim in the medical records of patients by health care providers; 27 semi-structured interviews were carried out and re-transcribed. Eighteen patients were encountered on D0 for a first interview (within 48 hours of the initial request), nine of whom took part in a second interview on D7 (a week later). In the intervening period between the two sets of interviews, six patients died, whilst three were either too fatigued or too disorientated to be interviewed a second time.

Twelve patients were suffering from terminal cancer, three from a neurodegenerative disorder (amyotrophic lateral sclerosis), one from severe arterial and pulmonary hypertension and two had cardiovascular or hepatic disorders. Their average age was 76 years (from 38 to 95 years) with a median of 79 years.

\begin{tabular}{|c|c|}
\hline Number of patients identified from medical records & 31 \\
\hline $\begin{array}{c}\text { Number of patients encountered during } 1^{\text {st }} \text { round of interviews } \\
\text { (D 0) }\end{array}$ & 18 \\
\hline $\begin{array}{c}\text { Number of patients encountered during } 2^{\text {nd }} \text { round of interviews } \\
\text { (D7) }\end{array}$ & 9 \\
\hline Total number of interviews & 27 \\
\hline
\end{tabular}

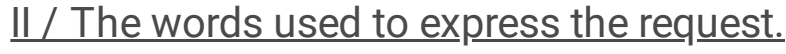

\section{A - The initial request reported by the health care provider in the patient's medical records (31 records).}

Request for euthanasia

The terms of the initial request were primarily requests for euthanasia: "Yes, it's a request for euthanasia" [RIF9]. Only one initial request related to assisted suicide: "If only I could just swallow something and then go" [REF8]. Two statements referred to euthanasia whilst mixing the representations 
of euthanasia with those of assisted suicide: "I want to have euthanasia in Switzerland" [REF1], "Can you put me down, can you inject me with some stuff so I can die" [REF10].

The injection as a dominant picture.

The predominate image is of injection or intravenous infusion ("injection", "inject me", "drip"): "if you were to give me an injection, that would be good" [REF4], "give me an (gesture an sound of injection)" [REF6], "for the drug to be injected" [REF9], "When are you going to give me the injection, will I have to wait long?" [REF11], "I want to be helped to die, I want a drip" [RIF19]. This method of carrying out the act can even serve as metonymy for the wording of the request: "for the drug to be injected" [REF9], "When are you going to give me the injection, will I have to wait long?"[REF11].

Request for help and demand for fulfilment.

Some words expressed a request for help, since the situation was frequently described as unbearable: "I really can't go on, I'm going to have a ciggy with my partner, and then I'd like you to inject the drug" [REF9].

Eleven occurrences of words stated a clear request for help: "help me", "help", "the help". Other requests come in the form of demands: "If you could put me down" [REF7]; "Could you give me some more morphine, if so give me a (gesture and sound of injection) at the same time" [REF6]. Words which state a demand appear eight times: "Give me", "Do" and terms relating to the wish appear ten times: "I want".

The time imperative is seen as urgent.

A third of the requests express the idea of expediency, "that's enough of this, I'm fed up with it, nothing's being done to relieve me, it's time to put an end to my life" [RIF6], "It's got to be done as quick as possible" [RIF8]. The analysis of the number of times each of the patient's words occurs revealed 12 uses of time adverbials: "quick", "rapidly", "immediately", or time requisites which situate the action in the very near-future: "this afternoon", "tomorrow".

\section{B - The request for help to die in the interviews.}

1 - First interview (D0): The request for help to die associated with the altered relationship with the body and the request for a third party to actively intervene. 
The active request for help to die was frequently expressed as justified or legitimate in the light of a state of suffering which had gone beyond what could be reasonably endured: "I can't move anymore, nor get up, I can't do anything anymore. At 89, you should be able to put us down [...] A vegetable, I'm nothing more than a vegetable" [REF7]. Preemptive death was likewise expressed as justifiable when there was no more hope of cure or when "there's nothing more at the end" [REF8]. Being denied their request was perceived as inhuman: "It's inhuman to let people suffer like this" [REF5]. Self determination was asserted particularly in relation to the body: "It's my body, they can't say what they want or don't want for me" [REF9].

Living the formidable experience of changes in the relationship to their body brought the patient face to face with their own individuality. No one could suffer like them and assess what they were really feeling. This state of intense suffering isolated them and made them feel as though they were in "another world": "I'm not on the same planet anymore. I look at them, I'm not part of their world anymore [...] this death is going to happen so you just have to accept it" [REF5].

The determined quest for euthanasia.

Words can express the wish: "I'd like euthanasia [...] I'm certain" [REF8], "I want", "I've made up my mind", "I won't go back on my decision", "I'm still determined". These verbatim also conveyed a desire to convince the third party of their determination, which was illustrated by the frequent use of the pronoun "I". Some patients expressed their resolution by asserting it as a long held opinion, as opposed to a fleeting reaction: they had "always been for" or they had never wanted to suffer: "I've always thought about euthanasia but now it's worse than anything ever" [REF8].

The request for euthanasia was concrete and expressed either as a request for help or as an act to be performed by a third party: "do..." or "help me to go", "Give me an injection". The patients were aware that it would be illegal for the health care provider to intervene by granting their request: "It'll have to be a doctor who's $100 \%$ in favour, of course. As whoever does it, well you mustn't shout it from the rooftops, as they'll risk their job" [REF8].

2 - Second interview (D7): Maintaining the request but a shift towards the question of suicide.

The request persisted, but less explicitly.

Two thirds of the patients encountered a week later persisted in their WTHD: "I haven't changed my mind, I should be free to decide [...] every day I think about ending it" [REF8]. Whilst the request still featured implicitly in the dialogues, it was less prevalent in spontaneous speech and appeared less agonistic than previously. However, when the patient was questioned about previous conversations, the desire was still present: "If you ask me, yes I think about it every day [...] and if tomorrow you say 
euthanasia's on, it's yes" [REF3]. The issue of legitimacy, or personal autonomy, of the act was still doggedly upheld. The patients were convinced of their right to death-on-demand: "You should be allowed to choose [...] You should be free" [REF8].

The wish to shorten their lifespan was still expressed but no longer in the form of an injunction. The appeal for help, which was explicit in the first round of interviews, was not evident in the second round. Words occurred which indicated a form of resignation in the face of death: "There's no hope left, I'm going to die, I know I am" [REF6]. The meaning of life was also in queried: "What purpose does my life serve with all that? It's not a life" [REF3].

A shift towards the issue of suicide and the fear of not succeeding.

At D7, only 2 patients still clung to the idea of euthanasia. The word suicide appeared more often, presented as a means of attaining their aims: "It'll have to be by pill" [REF3], "I think a lot about suicide" [REF8].

This was also associated with fear: "If I go home, I'm scared I'll do something stupid [tears] The stupid thing would be to kill myself" [REF3].

One female patient even worded a request for assisted suicide in such a way as to ensure the act was carried out 'safely'; "It would have to be someone who'd give me... a dose or whatever. But, I understand a doctor couldn't carry out the act, yet it's not the act you're asking for, it's that he simply gives us what we have to take, and then, just, well, that he supplies us" [REF8]. The relative thought of committing to the action remained a source of anxiety. Whilst the majority of patients appeared determined, they mentioned their fear of failing when carrying out the act of suicide: "You'd have to know what dose to take so you don't mess it up or anything" [REF8]. Patients expressed fear of not succeeding or 'messing up': "I think about it but I'm scared of messing it up, then I say to myself 'and what if I mess it up' ...[tears]" [REF3]. This notion of suicide was often stripped of any possible reality, as illustrated by the patient who said: "Give me the syringe, I'll do the injection if you like" [RIF7], but who had been tetraplegic for many years and would have been incapable of actually carrying out what she was implying.

\section{C- Representations of death in the interviews.}

1 - First interview (D0): a rapid death without suffering

A request expressing the wish for the act to be carried out rapidly 
The majority of patients expressed a wish for euthanasia, whilst for two of them it seemed to fluctuate: the patient expressing that he could change his mind from one hour to the next: "in the midst of an attack, there I am saying, 'give me the injection right now', then well, 5 minutes later, I'd be saying, 'what an idiot I was" [RIF3]. Likewise, for patient REF1, who only communicated in writing showed the thread of his thinking on his telephone: "12h24: I want to go to Switzerland to have euthanasia/ 17h28: I don't want to die anymore".

A first category of wording asserted the desire to shorten their lifespan: "get it over", "quick", "I don't want it to linger on, I want to go quickly" [REF6], "Have it end as quick as possible, meaning not adding anything, no drugs" [REF5]. The real wish that "it end", "there's nothing can be done, what do you want to do? Wait, wait. Just get on and give me the injection or whatever and have it end" [REF4] may have been motivated by the loss of any meaning to existence.

Several wordings were formulated by designating "it" as death and/or the desired act: "It will have to happen quickly" [...] I want it to happen when I'm choking" [REF6]. It refereed to something indistinguishable, similar to putting a name to an unknown phenomenon.

Aspiring to a gentle death

The majority of patients did not express the manner in which they wanted their request to be executed. Generally, they wished for a gentle or unconscious death "to go to sleep and not wake up" [RIF1], "like sleeping" [RIF10]. Many patients dreaded the episodes of intense pain and the choking fits: "What scares me is having moments of panic, suffocating [...] I'm scared of going in terrible suffering" [REF6]. This justified the appropriate moment for carrying out the act: "It was when I was choking that they should have ended it all" [REF5]. This anxiety was often associated with experiences related to the violent death of a loved one: "I'm well aware of the reality of severe illness, I watched my mother die suffering dreadfully" [REF5]. They mentioned that the ideal way to die would be to go to sleep, not wake up and die painlessly.

Two patients, only, voiced the idea of an injection in this round of interviews: "that I'm given an injection or whatever else and then it's over" [REF4] and one [REF5] contemplated deep, continuous sedation until death.

2 - Second interview (D7) : Trauma of witnessing the conditions of a relative's death. 
During the second round of interviews, whilst the patients' request for help to die was no longer as concrete, the memory of being confronted with the illness and subsequent death of a relative remained in their words. It related to the fear of dying in the same suffering, in the same conditions as the person they had cared for. The traumatic event came back to haunt them: "Dying doesn't frighten me, suffering like my father did when he died, that frightens me. If death came to take me away, then it'd be a relief" [REF3].

\section{Discussion}

The fact that a patient's inclusion in the study was reliant on the health care provider meant that access to some situations was limited. Added to that, the requests concerned patients facing imminent death, and therefore at their most vulnerable. Most of the patients died in the days following our encounters. It would be interesting to extend this study beyond the palliative setting to other patient populations. By the same token, it is not an easy task interviewing patients on this theme, yet it is important to emphasise that all the interviews were well received by all parties concerned. Everyone mentioned how beneficial it was psychologically to be able to speak on this sensitive subject without being judged. These individuals gave us the means to get to know them, acknowledge them and understand them.

A patient's Request for Euthanasia or Assisted Suicide (REAS) was always directed at a health care provider with an expectation, that of having them accomplish something forthem. It was therefore grounded in an interaction.

Narration took on a real function; that of being able to attribute meaning to previously inconceived, complex and challenging tribulations, which compromised the individual experiencing them. More precisely, by putting it into words it became possible to organise the experience within a time frame. Finally, beyond what the words and acts were actually stating, through the expression of their suffering, there is also the question of precisely what was being vented by the grievances of these patients. The discourse analysis shows that the patients, by speaking about something which is outlawed in France, were attempting to signify a vitally important issue affecting them personally using their words.

The words translated at the same time the person's sense of anxiety over an imminent event, which they were powerless to prevent and which was leading them towards an unknown destination.

Representations of the act, particularly those in the initial statements reported by the health care providers, adhered to everyday practices ("injection", "give something").

Metonyms used, such as "injection" for the act of bringing about death and "it" for death, are means of avoiding something you do not wish to name or something which you are unable to apprehend. Anselm Strauss ${ }^{11}$ states that it is also a means of avoiding excessive emotional outbursts, to keep up appearances. The unsaid is supposed to guard against the excesses, awkwardness and distress which a preemptive death could allow to go unfettered ${ }^{12}$.

It can be seen that whilst the wording evolves over time, the will it expresses often persists. The expression of the WTHD frequently translated into a will grounded in individual convictions derived from 
personal experiences. This could account for the extent to which the death of a loved one, or even more so the conditions of their death, may have influenced the way a person visualised their own death.

The specific vulnerability of patients in PCU we encountered accounted for the fact that of the 31 REAS situations reported, only 9 patients were able to participate in an interview at D7; the others had died or were incapable of communicating. Whilst the request to die persisted in the majority of the interviews at D7, the words used to say it had changed from a request for euthanasia to a request for assisted suicide, which was more explicit and less euphemistic.So our findings partially reproduce the results of Van der Maas et al. which indicated a fluctuation in the wish to die $^{13}$ following a palliative intervention, with $67 \%$ of patients renouncing their intention to hasten death following a palliative intervention. Whilst the patients' wordings in our study were not fixed, the majority adhered to a stable time-frame and the patients had not given up on their intention to hasten death. It could be considered that the development over time towards a request for assisted suicide reflects a veritable psychological development by the patients. Thus the patient would appear to reassert themselves, and find autonomy.

Furthermore, we observed that a concrete fulfilment of the request for help to die was primarily associated with a rapid, gentle death. Dying unaware was considered the ideal preemptive death. It was even considered an imperative for an end to suffering. Several studies have shown that pain crises, ${ }^{14}{ }^{15}$, the fear of choking ${ }^{16}$, and panic are events which cause patients the most intense mental distress and provoke growing anxiety. Most patients found justification for their request to hasten death in the relief of not having to experience and re-experience these traumatic events. As indicated by R. Gamlin and M. Bondier et al, our findings showed that ultimately patients wished to have the capacity to choose, to reclaim a sense of self-ownership ${ }^{17}$, to have power over their own decisions ${ }^{18}$ and their own body as the ultimate space of freedom.

We also found in the patients we encountered at the end of life that they wanted the time remaining to them to be steeped in quality. In fact, they were aspiring to the conditions of a "good death".. This question relates to $P$. Hintermeyer's inquiry into the issue of dignity and the dimension of human meaning ${ }^{19}$. This aspect relating to the question of the good death and the consequential relief from suffering is central: the patients viewed the practice of euthanasia not as killing, but as relieving. Therefore, the requests were embedded in time and constructed from representations of the conditions of death, acceptable or unacceptable.

\section{Conclusion}

Whilst euthanasia and assisted suicide are forbidden by French law, the desire to hasten death is a reality in palliative care in France ${ }^{20}$. In order to help the individual put meaning to what they are feeling, it is essential to really listen to and attempt to understand precisely, and in all its uniqueness, what it is they are saying. If patients speak of their request for help to die, it is because they need a third party to listen to and hear them. Conducting interviews on this delicate topic is not easy but attentive listening and a 
real will to understand makes for a favourable encounter with the unique other and enables complex issues to be addressed.

The words used are the keys to understanding for the health care providers. The individuals are thus compelled to find common concerns in the dialogue. The dialogue then becomes the space where the answers can be found, the appropriate space for understanding the common construction. The danger resides in a third party overinterpreting what the person is attempting to express with their words.

The utterances of a person who asks to die is an attempt to express the unutterable, an attempt at expressing individual suffering. It is vital to question the purpose of the utterance, the very thing which is at issue. The expectation is both diverse and ambiguous, if not ambivalent. This approach reinforces the possibility of not focusing exclusively on the act to be undertaken but also on communication and the relationship between caregiver and patient.

\section{Annex}

Due to technical limitations, the Annex section could not be displayed here. Please see the supplementary files to access it.

\section{Abbreviations Section}

ANSM: National Agency for the Safety of Medicines and health products

AS: request for Assisted Suicide

CPP: Committee for the Protection of Persons

PCU: Palliative Care Unit

RE: Request for Euthanasia

REAS: Requests for Euthanasia and Assisted Suicide

REF: Region East France

RIF: Region lle de France. Paris and the surrounding region

WTHD: Wish To Hasten Death

\section{Declarations}

Ethics approval and consent to participate 
This study received the favorable opinion of the committee for the Protection of Persons (CPP Est II) on 15/05/2014 and the National Agency for the Safety of Medicines and Health Products (ANSM) on 09/05/2014, in accordance with the legislation in force in France.

All patients signed an information note and consent to participate in the study and the publication of the results

\section{Consent for publication}

All patients signed an information note and consent to participate in the study and the publication of the results

\section{Availability of data and material}

The study protocol and data are available on request from the Clinical Investigation Centre (INSERM 1431), University Hospital of Besançon (France).

\section{Competing interests}

Authors do not declare conflicts of interest.

\section{Funding}

Fondation de France

Défenseur des droits

Fonds pour les soins palliatifs

Fondation Bettencourt-Schueller

\section{Author's contributions}

- FMN has made substantial contributions to the conception; has made the acquisition, analysis; has made interpretation of data; has drafted the work.

- AC has made substantial contributions to the conception; has made the acquisition, analysis; has made interpretation of data; has substantively revised the work.

- DL has made the acquisition, analysis; has made interpretation of data; has substantively revised the work.

- $A B$ has made the acquisition, analysis; has made interpretation of data; has substantively revised the work.

- AGM has made interpretation of data, has substantively revised the work. 
- HT has made interpretation of data, has substantively revised the work.

- FG has made interpretation of data, has substantively revised the work.

- EC has made the design of the work, has made interpretation of data, has substantively revised the work.

- RA has made substantial contributions to the conception, has substantively revised the work

All authors have read and approved the manuscript

Acknowledgements

The authors would like to thank the patients who agreed to participate in the study; the caregivers who included and participated in the study;

\section{Clinical Trials}

- Name of the registry. : Requests for Euthanasia and Assisted Suicide (DESA)

- Trial registration number : gov Identifier: NCT02845817

- Date of registration: July 27,2016, Retrospectively registered' :

- URL of trial registry record : https://clinicaltrials.gov/ct2/show/NCT02845817? term $=$ desa\&draw $=2 \&$ rank $=1$

\section{References}

1 Kelly B, Burnett P, Pelusi D, et al. Factors associated with the wish to hasten death: A study of patients with terminal illness. Psychol Med 2003;33:75-81; Guirimand Frédéric, Dubois Etienne, Laporte Lucy, et al. Death wishes and explicit requests for euthanasia in a palliative care hospital: an analysis of patients files. BMC Palliative Care, 2014, vol. 13, p. 53. ; FERRAND ; Ly et Aubry, 2015

2. Monforte-Royo, C., Villavicencio-Chávez, C., Tomás-Sábado, J., Mahtani-Chugani, V., \& Balaguer, A. (2012). What lies behind the wish to hasten death? A systematic review and meta-ethnography from the perspective of patients. PLoS One, 7(5), e37117.

3. Rodríguez-Prat, A., Balaguer, A., Booth, A., \& Monforte-Royo, C. (2017). Understanding patients' experiences of the wish to hasten death: an updated and expanded systematic review and metaethnography. BMJ open, 7(9), e016659.

4. Ohnsorge, K., Gudat, H., \& Rehmann-Sutter, C. (2014). What a wish to die can mean: reasons, meanings and functions of wishes to die, reported from 30 qualitative case studies of terminally ill cancer patients in palliative care. BMC palliative care, 13(1), 38. 
5. Coyle, N., \& Sculco, L. (2004, July). Expressed desire for hastened death in seven patients living with advanced cancer: a phenomenologic inquiry. In Oncology nursing forum (Vol. 31, No. 4).

6. Nissim, R., Gagliese, L., \& Rodin, G. (2009). The desire for hastened death in individuals with advanced cancer: a longitudinal qualitative study. Social science \& medicine, 69(2), 165-171.

7. DESA Study : « Requests of Euthanasia and Assisted Suicide: Prospective, multicenter and qualitative study», University Hospital of Besançon, France. Ref Clinical Trials: NCT02845817. https://clinicaltrials.gov/ct2/show/NCT02845817?term=desa\&rank=1

8. Definitions opinion 121 National Consultative Ethics Committee in France: Euthanasia is "the act performed by a third party, intended to deliberately and intentionally end the life of a person suffering from a serious and incurable disease, at his request, in order to put an end to a situation which he considers unbearable"; Assisted suicide "consists in giving a person the means to commit suicide himself"; Assisted suicide "is when a person who wishes to end his or her life is not able to do so because of his or her physical condition, he or she needs the active assistance of a third party for the administration - by absorption or injection - of the lethal product to complete the decision".

9. 9. Ly S, Aubry R. What lies behind a request for euthanasia or assisted suicide? Single-centre, prospective, epidemiological study. Medpal 2015. 14, 1-13

10 Bousquet A., Guirimand F., Aubry R., Leboul D. Palliative care unit caregivers facing a euthanasia request: a qualitative pilot study. Médecine palliative 2016. 15, 4 -14

11 Strauss, A. L., \& Glaser, B. G. (1965). Awareness of dying. Chicago, Adline.

12 Hintermeyer, P. (2004). Les critères du bien mourir. Gérontologie et société, 27(1), 73-87.

13 van der Lee ML, van der Bom JG, Swarte NB, et al. Euthanasia and depression: A prospective cohort study among terminally ill cancer patients. J Clin Oncol 2005;23:6607-12

14 Seale C, Addington-Hall J. Euthanasia: Why people want to die earlier. Soc Sci Med 1994;39:647-54. 
15 Chochinov HM, Wilson KG, Enns M, et al. Desire for death in the terminally ill. Am J Psychiatry 1995;152:1185-91.

16 Chochinov HM, Tataryn D, Clinch JJ, Dudgeon D. Will to live in the terminally ill. Lancet 1999;354:8169.

17 Bondier, M., Mathieu-Nicot, F., Mariage, A., Bioy, A., \& Aubry, R. (2018, February). L'impact psychologique de la douleur en soins palliatifs: entre majoration de l'angoisse de mort et renforcement du sentiment d'existence, un impact psychologique complexe. In Annales Médico-psychologiques, revue psychiatrique (Vol. 176, No. 2, pp. 157-162). Elsevier Masson.

18 Gamlin R. Signification de la dignité en soins palliatifs. Eur J Palliat Care 1998;5:187-90

19 Hintermeyer, P. (2003). Euthanasie, la dignité en question. Buchet Chastel.

20 Guirimand, F., Dubois, E., Laporte, L., Richard, J. F., \& Leboul, D. (2014). Souhaits de mort et de demande explicite de l'euthanasie dans un hôpital de soins palliatifs: une analyse des dossiers des patients. BMC Palliative Care, 13, 53.

\section{Consort}

DESA study adheres to CONSORT guidelines.

\section{Key Statements}

\section{What is already known about the topic?}

- No studies have analyzed the wording of these patient requests in interviews and representations associated with death.

- Patients in palliative care may express a desire to hasten their death. 
- Empirical studies (in countries where euthanasia or assisted suicide is possible) focus mainly on the frequency of these requests as well as their reasons and meaning.

- These requests may change over time.

- Requests for euthanasia can be related to pain, suffering, loss of hope, loss of control, feeling unworthy and being a burden to others

\section{What this paper adds?}

- The request for death assistance explicitly requires the intervention of a third party in the first place: these are requests for euthanasia.

- Secondly, the request is less explicit and requires less intervention by a third party

- This study highlights the representations of the act of euthanasia or assisted suicide as well as the representations of death in the patients met.

- This study sheds light on the lexical field to express the request for euthanasia or assisted suicide, the modalities and the meaning.

- The picture of the injection is predominant among patients and the relationship to time is experienced as an emergency.

\section{Implications for practice, theory or policy}

- For health care providers, the words used are the keys to understanding and help to find common concerns. Dialogue then becomes the space where answers can be found.

- This approach reinforces the possibility of not focusing exclusively on the act to be performed, but also on communication and the relationship between the caregiver and the patient.

- To help the individual to give meaning to what he or she feels, it is essential to listen and try to understand precisely, and in all its uniqueness, what he or she is saying.

\section{Supplementary Files}

This is a list of supplementary files associated with this preprint. Click to download.

- CONSORT2010Checklist.doc

- Annex.docx 